\title{
Changes in social inequalities in health in the Basque Country
}

\author{
Cecilia Anitua, Santiago Esnaola
}

\begin{abstract}
Study objective-To determine the extent of the inequalities in self reported health between socioeconomic groups and its changes over time in the Basque Country (Spain).

Design-Cross sectional data on the association between occupation, education and income and three health indicators was obtained from the Basque Health Surveys of 1986 and 1992. Representative population samples were analysed. In 1986 the number of respondents was 24657 and in 1992, 13277.

Setting-Basque Country, Spain.

Main outcome measures-The effect of socioeconomic position on health and the magnitude of social inequalities in health were quantified using the odds ratios based on logistic regression analysis, and the Relative Index of Inequality.

Results-As was expected, social inequalities in self reported health existed in both surveys, but the social gradient was greater in 1992. Social differences varied according to gender and health indicator. According to education an increase in social inequalities was observed consistently in all the health indicators except long term conditions in women. A consistent increase in inequalities in limiting longstanding illness was also observed according to all socioeconomic indicators. Conclusions-These results agree to a large extent with those of previous studies in other countries. In this context the unequal distribution of material circumstances and working conditions between socioeconomic groups seem to play a major part in health inequalities. The worsening of the labour market during this period and the onset of a new economic recession may explain the increase in social inequalities over time. (F Epidemiol Community Health 2000;54:437-443)
\end{abstract}

Research Unit, Department of Health, Basque Government

Correspondence to: Dr Anitua, Departamento de Sanidad, Gobierno Vasco, Donostia-San Sebastián 1, 01010 Vitoria-Gasteiz, Spain (escav-san@ej-gv.es)

Accepted for publication 30 November 1999
The existence of inequalities in health between socioeconomic groups has been largely reported. ${ }^{1-6}$ Studies of this issue are infrequent in Southern Europe, partly because of the scarcity of health statistics including socioeconomic variables. ${ }^{7}$ Particularly, in Spain the quality of socioeconomic data in the register of mortality has been questioned, ${ }^{8}$ and information on inequalities in health has been made available just recently. ${ }^{9-11}$

Traditionally, most attention has been given to inequalities in mortality. However, it can be argued that, when absolute rates of premature mortality are low, lifelong experience of health and illness differentiate more clearly between those who are more or less fortunate. ${ }^{12}$ The interest in a person's assessment of his own health status has been rising, both because it might be a useful measure to assess the overall health of a community, and because of the current concern with behavioural and psychosocial factors in the incidence, prognosis and mortality of chronic diseases. ${ }^{13}$ Moreover, health services now are increasingly concerned with non-life threatening conditions; so even though mortality data are more available, the analysis of self perceived health is relevant to the provision of health services.

Reducing social inequalities in health is a major goal expressed in the health policies of most European countries. ${ }^{14}{ }^{15}$ Nevertheless, no effective policies have been carried out, and in some European countries social differences in health have even increased. ${ }^{4-61617}$ Unfortunately, only very few studies centred their attention on trends in social inequalities in morbidity, ${ }^{6}{ }^{18-23}$ and only one focused its attention on Southern European countries. ${ }^{22}$ In fact, there is a great need for studies of trends in social inequalities with both mortality and morbidity data in these countries. The interest in monitoring trends is even greater when costs containment is on the agenda of health services planners throughout Europe, and important social structural changes have been taken place in the Basque Country.

The Basque Country (North of Spain) is currently considered to be a declining industrial region. During the period 1986-1991, coinciding with entry into the European Common Market, there was sharp increase in the economy, larger than the one observed in Spain or in Europe. The absolute number of employed people rose continuously, and government welfare expenditures contributed to the redistribution of income. Despite the decrease in the number of students, education expenditure rose from $4.39 \%$ of the gross domestic product in 1982 to $5.73 \%$ in 1993, and this increase being especially important at a university level ${ }^{24}$ (the number of university students rose from 46446 in 1986 to 75521 in 1992). ${ }^{25}$ In 1992-1994 a new recession cycle took place, and unemployment rose from $17 \%$ in 1991 to $20 \%$ in 1992 .

According to the Basque Statistical Office, ${ }^{25}$ important changes in the sociodemographic characteristics of the population were observed during the study period. There was a reduction in the number of inhabitants (2 136100 to 2104041 ), the population was older, educational qualifications increased, and the birth 
rate decreased (9.4 to 7.7 per 1000 inhabitants). Life expectancy in men (72.4 to 72.8 years) and in women (79.7 to 81.5 years) rose, while the infant mortality rate was reduced (10.1 to 6.7 per 1000 live births).

These demographic and social structural changes would have had an effect on social inequalities in health. This study was carried out to measure the magnitude and the changes in social inequalities in self reported health in the Basque Country for the period 1986-1992.

\section{Methods}

DATA

The data were obtained from the Health Surveys of the Basque Country, carried out in 1986 and 1992 by the Department of Health of the Basque Government. Both surveys were cross sectional, based on large random samples of private households, covering the noninstitutionalised population of the Basque Country. Information was collected in face to face interviews, using a questionnaire designed to compile data from all members of the household, and proxy respondents (caregivers and spouses) were admitted. Data on morbidity, disability, and the use of health services were gathered.

The surveys presented some differences with regard to sample size and sample design. In 1986, 7200 households were selected by stratified random sampling, including 24657 people. In 1992, 500 census sections from 2000 were selected by stratified random sampling. At

Table 1 Characteristics of the study subjects by sex. Basque Health Surveys, 1986 and 1992

\begin{tabular}{|c|c|c|c|c|c|c|c|c|}
\hline & \multicolumn{4}{|l|}{1986} & \multicolumn{4}{|l|}{1992} \\
\hline & & \multicolumn{2}{|c|}{ Women } & \multicolumn{2}{|l|}{ Men } & \multicolumn{2}{|l|}{ Women } \\
\hline & $\%$ & $n$ & $\%$ & $n$ & $\%$ & $n$ & $\%$ & $n$ \\
\hline \multicolumn{9}{|l|}{ Age (y) } \\
\hline$<16$ & 23.8 & 2343 & 21.4 & 2683 & 17.5 & 1139 & 16.2 & 1092 \\
\hline $16-24$ & 15.4 & 1839 & 14.9 & 1867 & 16.7 & 1092 & 25.5 & 1047 \\
\hline $25-44$ & 25.9 & 3092 & 25.5 & 3194 & 29.5 & 1928 & 28.5 & 1923 \\
\hline $45-64$ & 25.3 & 3025 & 24.8 & 3109 & 25.1 & 1639 & 24.4 & 1648 \\
\hline$\geqslant 65$ & 9.7 & 1154 & 13.4 & 1683 & 11.2 & 731 & 15.3 & 1032 \\
\hline \multicolumn{9}{|l|}{ Occupational class } \\
\hline Class I (high) & 4.8 & 578 & 4.7 & 587 & 9.9 & 665 & 10.7 & 701 \\
\hline Class II & 13.5 & 1618 & 13.4 & 1685 & 9.9 & 666 & 9.7 & 630 \\
\hline Class III & 19.5 & 2221 & 17.3 & 2181 & 13.7 & 924 & 13.2 & 864 \\
\hline Class IV & 46.9 & 5632 & 48.1 & 6054 & 41.3 & 2781 & 41.0 & 2679 \\
\hline Class V (low) & 16.4 & 1964 & 16.6 & 2087 & 25.3 & 1706 & 25.4 & 1655 \\
\hline \multicolumn{9}{|l|}{ Education } \\
\hline \multicolumn{9}{|l|}{$>16$ years } \\
\hline Higher & 9.5 & 869 & 5.6 & 1094 & 14.4 & 486 & 13.0 & 733 \\
\hline Secondary & 19.2 & 1747 & 15.3 & 1510 & 23.8 & 1285 & 19.5 & 1100 \\
\hline Basic & 71.3 & 6489 & 79.0 & 7781 & 61.0 & 3319 & 67.5 & 3817 \\
\hline \multicolumn{9}{|l|}{$>45$ years } \\
\hline Higher & 8.0 & 334 & 2.9 & 140 & 8.6 & 203 & 3.7 & 98 \\
\hline Secondary & 6.9 & 290 & 2.8 & 132 & 8.7 & 205 & 3.9 & 105 \\
\hline Basic & 85.1 & 3555 & 94.3 & 4516 & 83.4 & 1982 & 92.4 & 2477 \\
\hline \multicolumn{9}{|l|}{ Income } \\
\hline 4th quartile (high) & 21.0 & 2085 & 20.2 & 2022 & 23.4 & 1271 & 21.7 & 1227 \\
\hline 3rd quartile & 32.8 & 3250 & 31.3 & 3126 & 19.3 & 1051 & 18.4 & 1036 \\
\hline 2nd quartile & 33.2 & 3284 & 32.6 & 3260 & 39.9 & 2166 & 37.4 & 2108 \\
\hline 1st quartile (low) & 13.0 & 1282 & 15.8 & 1581 & 17.4 & 946 & 22.5 & 1272 \\
\hline \multicolumn{9}{|l|}{ Employment status } \\
\hline \multicolumn{9}{|l|}{$>16$ years } \\
\hline $\begin{array}{l}\text { Paid } \\
\text { employment }\end{array}$ & 61.6 & 5548 & 19.5 & 1876 & 55.9 & 3015 & 26.0 & 1466 \\
\hline Housewives & 0.0 & 8 & 57.2 & 5502 & - & - & 48.0 & 2711 \\
\hline Unemployed & 9.4 & 843 & 5.2 & 498 & 10.1 & 544 & 6.0 & 341 \\
\hline Retired & 14.5 & 1307 & 6.2 & 605 & 20.6 & 1109 & 7.4 & 420 \\
\hline Other & 14.5 & 1304 & 11.8 & 1131 & 13.4 & 722 & 12.6 & 712 \\
\hline \multicolumn{9}{|c|}{ People in labour force } \\
\hline $\begin{array}{l}\text { Paid } \\
\text { employment }\end{array}$ & 81.4 & 5200 & 72.8 & 1727 & 82.2 & 2927 & 77.8 & 1406 \\
\hline Unemployed & 18.6 & 1191 & 27.2 & 647 & 17.8 & 632 & 22.2 & 401 \\
\hline
\end{tabular}

the second stage, eight households were drawn from each section, and 13280 people living in 4000 household were interviewed. The periods of fieldwork were also different. In 1986 the survey was carried out over a 12 month period, while the data for 1992 were collected from September to December. The response rates were $75 \%$ and $86 \%$ respectively.

\section{VARIABLES}

The socioeconomic position was measured by means of the current or past occupation of the head of the household, the income and the education. The occupational class of the head of the household was used because the participation of women in paid employment was very small, and because it has been argued that it is a better measure of the socioeconomic position than the occupation of women themselves. ${ }^{26} 27$ An ordinal scale of five groups was constructed with occupation. There were differences between the questions used in the two surveys. In 1986, the data on occupation were collected through a single open question. In 1992, three questions were used: the relation with the means of production (employer, employee), rank or category on a position scale, and activity sector (agriculture, industry, and services). Group I included professional and higher administrative occupations and employers (excluding agriculture), group II managerial and technical occupation, group III non-manual skilled, group IV manual skilled and partially skilled, and group V unskilled occupations. Education attainment, the highest examination passed by people aged more than 15 years, was classified in three categories. Higher is the equivalent of a university degree or an average of 13 years or more of education. Secondary requires an average of 9-12 years, and Basic equals less than 9 years. Household income was classified in four groups corresponding to the four quartiles in each survey. The nonresponse rate to this question was 19\% in 1986 and $17 \%$ in 1992 .

Three self reported health measures were analysed: restricted activity, limiting longstanding illness and chronic conditions. Restricted activity refers to a relatively short-term reduction in a person's activities below their normal capacity during the two weeks preceding the survey. Data from the last quarter of 1986 were selected to avoid seasonal variability between surveys in this indicator. Limiting longstanding illness consists of a long term reduction in a person's capacity to perform the kind or amount of activities associated with their age group. Several questions were asked according to the age of the respondent, following the structure of the US National Health Interview Survey. ${ }^{28}$ Because of differences between the surveys in questions relating to limiting longstanding illness for people aged above 65 years, only data on those aged fewer than 65 were analysed. The presence of a chronic condition was limited to mentioning one or more of those chronic conditions: cancer, respiratory diseases, heart diseases, diabetes, and musculoskeletal diseases. 


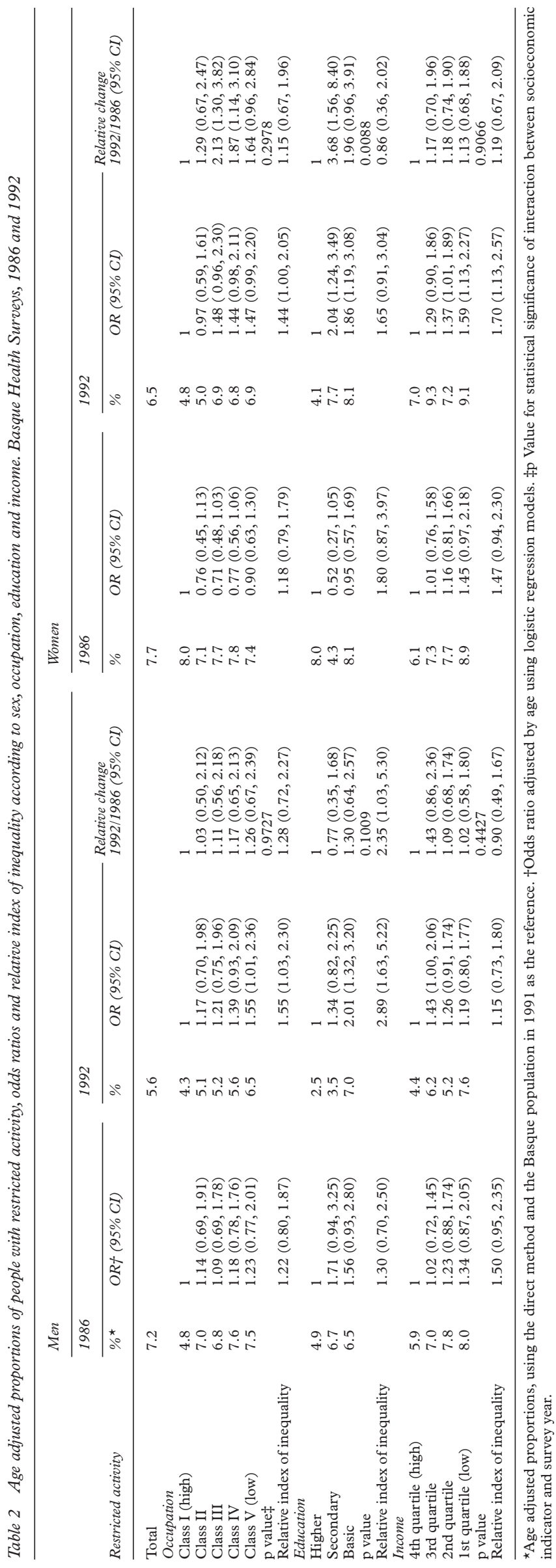

STATISTICAL ANALYSIS

Health indicators were standardised by age for each socioeconomic position, using the direct method (five year age band) and the Basque population in 1991 as the reference. The association between ill health and the socioeconomic group was assessed using logistic regression analysis of non-aggregated data. We estimated a separate model for each gender, and the socioeconomic group was included as a nominal variable. The effect of the socioeconomic group on health indicators was calculated by the age adjusted odds ratio (OR), group I being the reference. To obtain a precise measure of the changes in social inequalities between 1986 and 1992, a logistic model was fitted for each gender combining both surveys. The models included age (nominal variable, five age groups), socioeconomic group and the year of the survey as explanatory variables. The change in the magnitude of the inequalities between 1986 and 1992 was estimated by including an interaction term of the socioeconomic group and the variable, which identify the year of the survey in the model. This OR expressed the relative change in health differences between each socioeconomic group and group I from 1986 to 1992. The statistical significance of the interaction terms in the models is given in tables $2-4$.

To summarise and compare the total impact of social inequalities over time, an inequality summary measure was obtained: the Relative Index of Inequality. ${ }^{21}$ This measure takes into account the population distribution across socioeconomic groups. An assumption underlying the use of this index is the linearity of the rates across socioeconomic position. For the calculation of this index, socioeconomic status was quantified as the relative position of each subject in the socioecomomic hierarchy. ${ }^{21}$ This continuous measure was related to health indicators by means of logistic regression analysis. The age adjusted OR estimated the relative risk of ill health for those at the bottom of social scale compared with those at the top. The change in the Relative Index of Inequality was estimated by including an interaction term of the relative position and the variable, which identify the year of the survey in the model.

\section{Results}

In 1992, the study subjects were older and with a higher level of education than in 1986. However, the educational qualifications of those aged more than 45 years were very similar. The sizes of occupational groups were different, and very small changes were found with respect to employment status between both surveys. Women had lower education and income levels and a higher unemployment rate than men in both surveys. Women also showed the highest increase in the level of education between surveys (table 1 ).

Health status worsened as age increased and women had worse health than men did. The health indicators presented differences in the overall prevalence between surveys. Restricted activity decreased from 1986 to 1992 (7.5\% to 


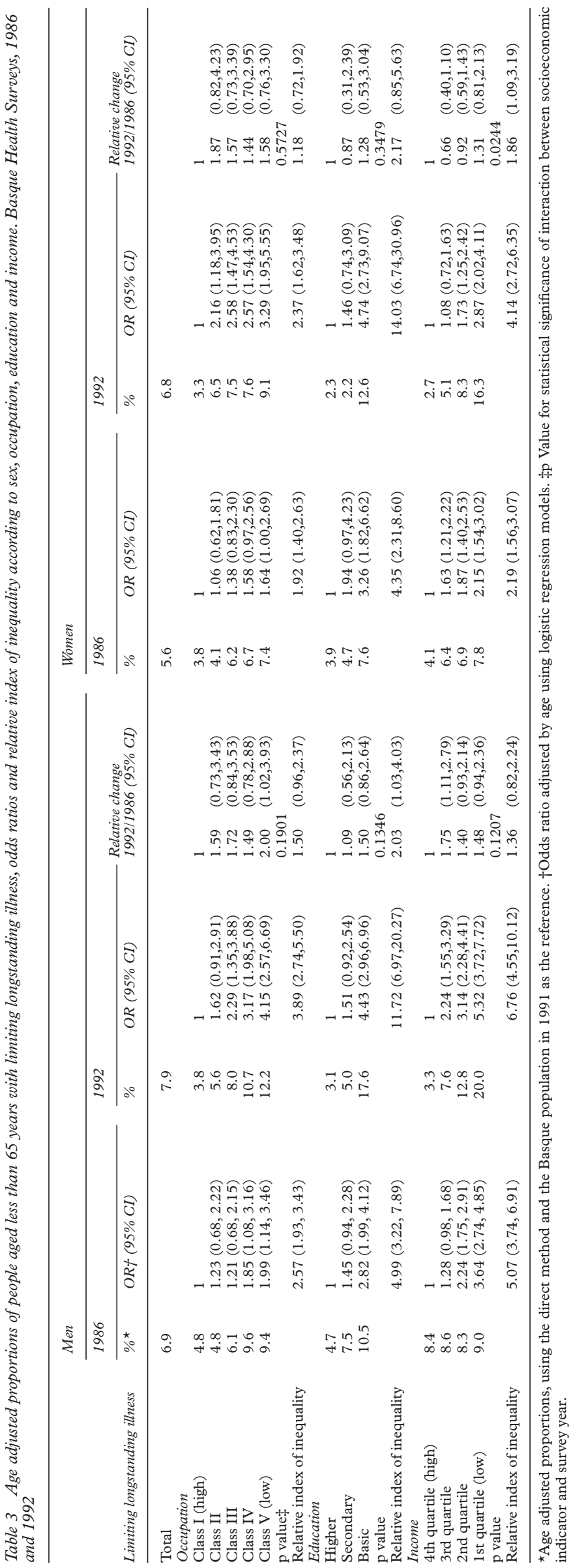

KEY POINTS

- Social inequalities in self reported health in the Basque Country were greater in 1992 than in 1986.

- The magnitude of differences in self reported health varied according to gender and socioeconomic indicator.

- Social inequalities seem to be related mainly to both material circumstances and working conditions.

- The worsening of the labour market and the onset of a new economic recession may explain the increase in social inequalities over time.

$6 \%$ and limiting longstanding illness and chronic conditions increased.

Table 2 shows the restricted activity indicator results. In 1986, social differences could be seen in men according to the three socioeconomic indicators, income showing the clearest social gradient. In 1992, in men, a clear social gradient was observed with occupation and education. In 1986, social differences in women were observed according to income, while in 1992, social differences were clear with respect to the three indicators. The results of logistic regression suggested an increase of the education effect on health in men and of both the education and occupation effects in women. The relative index of inequality increased in men according to education by 135\% (95\% CI: 3, 430).

Limiting longstanding illness had the clearest social gradient for both gender and in both surveys, and showed the greatest gender differences between surveys (table 3). According to logistic regression results, limiting longstanding illness showed the greatest increase over time in the effect of the three socioeconomic indicators on health in both genders. The relative index of inequalities rose in men and women with respect to all the socioeconomic indicators, the largest increase being according to education by $103 \%$ (95\% CI: 3, 303) and by $117 \%$ (95\% CI:-15, 463) in men and women respectively.

In 1986, men from the lower socioeconomic group showed higher prevalence in chronic conditions, and in women a clear monotonic social gradient of the age adjusted proportions was observed (table 4). Social differences were greater in women than in men according to occupation, but smaller according to education and income. The logistic regression results suggested an increase of the effect of education on health in men and of the effect of income in women. The relative index of inequalities increased in men according to education (44\%; $95 \%$ CI:-6,120). In women an slight increase was observed according to income $(23 \% ; 95 \%$ CI:-14,75).

\section{Discussion}

Social inequalities in self reported health existed in both surveys, and varied according to socioeconomic indicator, and gender. The steepest social gradient was observed when 


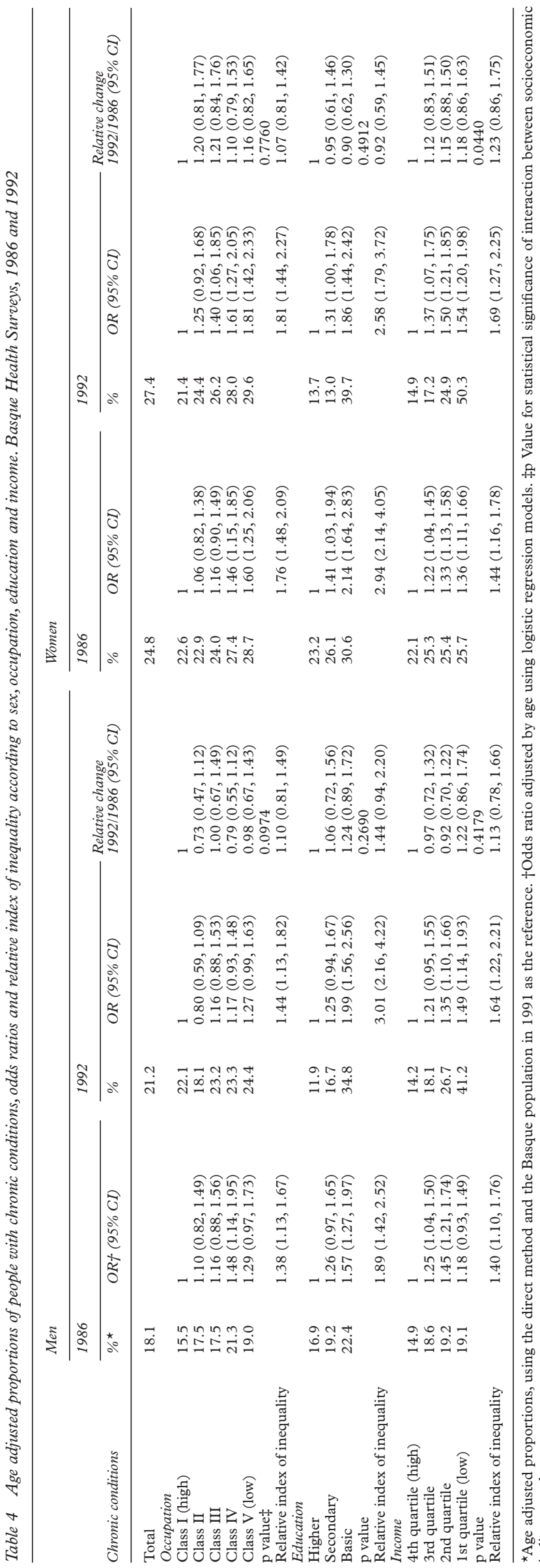

health status was measured in terms of limiting longstanding illness and social position by education for both men and women. According to education an increase in social inequalities was observed consistently in all the health indicators except chronic conditions in women. A consistent increase in inequalities in limiting longstanding illness was also observed according to all socioeconomic indicators.

The indicator of restricted activity showed a different trend over time to chronic conditions or limiting longstanding illness indicators. Changes in the labour market during this period, leading to more flexible employment, may have increased the financial pressures to continue one's daily activities in illness, and as a consequence, a reduction in the restricted activity rate. The increase in the overall prevalence of limiting longstanding illness and chronic conditions might be explained by the rise in social inequalities.

Both the effect of education on health and the total impact of social inequalities on the health status of the general population increased over time. Thus, the reduction of education differences in the general population during the study period did not compensate the larger effect of education on health.

Comparisons in time require considering the impact of the differences between surveys on the results. The non-response rate was satisfactory in 1986 but larger than in 1992. Evidence shows that the non-response is higher in lower socioeconomic groups, and is positively associated with current health status, but not consistently with the presence of chronic conditions or disabilities. ${ }^{29}$ Were non-response to lead to an underestimation of health inequalities, this bias would be larger in the restricted activity results, where changes in inequalities were less evident. Moreover, the increase in inequalities was not limited to lower groups, as it would be expected if the non-response were larger in those groups. As a consequence, the potential effect of the nonresponse on inequality estimates would be only modest.

Another important issue relates to differences between surveys in the socioeconomic indicators. A different question was used for occupation and the non-response rate for income was slightly greater in 1986 . However, a consistent increase was observed with education, which had both the same question and non-response rate in the two surveys.

Likewise, a major problem in estimating the increase in inequalities might arise if there were differences over time in the propensity of reporting health problems among people from lower socioeconomic groups. There is the possibility of a differential reporting over time. However, three health indicators reflecting different dimensions of health were analysed, and the increase in social inequalities was consistently found for each health indicator.

There is large evidence of social inequalities in self reported health according to the three socioeconomic indicators. Even if smaller inequalities in women than in men have been frequently observed, ${ }^{6} 122630-33$ the reversed 
pattern has also been found in some countries. ${ }^{30-33}$ The magnitude of the social differences varies according to health indicators: various studies did not show social differences in restricted activity ${ }^{3132} 34$ and a distinct pattern between men and women in this indicator was also noticed in other countries. ${ }^{32}{ }^{36}$ Moreover, in several studies larger social inequalities had been found according to limiting longstanding illness. ${ }^{18} 313235$

Studies of trends in social inequalities in morbidity are sparse and mostly refer to Northern Europe. ${ }^{6718-23}$ These investigations have used self reported health from health surveys to assess trends in inequalities in health, though the results obtained are not concordant. In Finland, an analysis of economically active people showed a drop in social inequalities in limited longstanding illness from 1964 to $1987 .{ }^{19}$ Moreover, from 1986 to 1994 and coinciding with an adverse economic recession, differences in limiting longstanding illness had been levelled off by education among Finnish adult population. ${ }^{23}$ In Great Britain, an increase in health inequality between social groups was observed with General Household data from 1970 to $1984 .{ }^{20}$ In the Netherlands, a slight increase in social inequalities in self perceived health was observed from 1983 to 1991. ${ }^{21}$ In Barcelona (Spain), from 1983 to 1992 different results were obtained according to the indicator: a decrease was observed in inequalities in self perceived health and restricted activity, but an increase in inequalities in chronic illness. ${ }^{22}$ In Spain, data from the same period as our study also showed an increase in social inequalities when analysing obesity trends through National Health Survey data. ${ }^{38}$

Social inequalities in health are associated with socioeconomic position through direct and indirect mechanisms linked to material circumstances, working conditions and health related behaviours. ${ }^{39} 40$ The material circumstances of the household are mainly related to the employment status and occupation of the head of the household. Unemployment rates showed a clear social gradient in our data. The probability of being unemployed was $112 \%$ higher in the lowest occupational group compared with the most well off. In our study, income differences linked to both the occupational hierarchy and the unequal distribution of unemployment between socioeconomic groups may explain health inequalities. In fact, income inequalities in the Basque Country are among the highest of Europe.$^{41}$ However, relative poverty is not the only link between health and unemployment. Unemployment also creates psychological distress and induces unhealthy behaviour. ${ }^{42}$ Nevertheless, in our context, health related behaviours might play a minor part. As in other Southern European countries, people in lower socioeconomic positions did not smoke more and did not drink more, and despite some changes, the pattern in these risk behaviours had not reversed. ${ }^{43}$

The effect of bad working environment on the health of the working population, and the contribution of working conditions to explain the socioeconomic gradient has been established..$^{39-46}$ The larger socioeconomic inequalities observed in men according to limiting longstanding illness and occupation suggest the importance of this factor in our data. Indeed, the limiting longstanding illness indicator measures functional capacity to work. Men's greater exposure both to worse physical environment and more physically demanding jobs, and their greater participation in the labour force may be relevant to explain the inequalities in limiting longstanding illness according to occupation.

It is probable that the changes in the labour market and the emergence of the economic recession could explain the rise in social differences in health. During the study period there was a huge rise in precarious employment, larger than that observed in Europe. The number of flexible contracts rose from $10 \%$ in 1987 (first data available), to $28 \%$ in 1992 . In addition, in 1992, a sharp increase in the unemployment rates was observed. However, income inequalities and unemployment were not larger in 1992 than in 1986. The reduction over most of the study period in both unemployment and income inequalities ${ }^{41}$ would offset the latter increase. ${ }^{47}$ Thus, the role of material insecurity in the increase in health inequalities seems more relevant. ${ }^{48}$ Moreover, these influences may be even more important than material circumstances, when basic living standards have been attained. ${ }^{48}{ }^{49} \mathrm{In}$ the Basque Country, the rise in flexible employment and the onset of the economic crisis increased material insecurity. As a result, those economically less well off would have augmented their chronic emotional stress, leading to a rise in the rates of illness. Whatever the pathway, be this direct or indirect, that linked socioeconomic situation to the health of the population, the new economic situation may have contributed to the increase in social inequalities in health.

The traditional class framework seems inadequate to explain social inequalities in health in women. To fully understand the mechanisms playing a part in social inequalities in women, both the gender differences in employment, and the interactions between employment and women's parental and marital roles had to be taken into account.

In the Basque Country, those in more favoured socioeconomic circumstances had better health than those less favoured and these differences increased over time. To explain these results, two main factors may have played a major part: the unequal distribution of income and working conditions. The worsening of the labour market during this period and the onset of a new economic recession may explain the increase in social inequalities over time. Further longitudinal studies are required to understand the contribution of working conditions and unemployment on socioeconomic inequalities in health, and the factors affecting social inequalities in women.

We are indebted to Carme Borrell and to Richard Wilkinson for their helpful comments on an earlier draft of this paper, and to 
Koldo Hualde for having shared with us his knowledge on the economic situation in the Basque Country. We also thank anonymous reviewers for their many constructive comments on
an earlier version of the paper. The views reflected in this paper an earlier version of the paper. The views reflected in this paper
are those of the authors alone, and do not necessarily reflect the are those of the authors al
views of their employers. views of their employers.

1 Fox J, ed. Health inequalities in European countries. Aldeshot: Gower, 1989.

2 Illsey R, Svensson PG. Social inequalities in health. Soc Sci Med 1990;31 (special issue):223-40.

3 Marmot MG, Kogevinas M, Elston MA. Social/economic status and disease. Ann Rev Public Health 1987;8:111-15.

Marmot ME, McDowall ME. Mortality decline and widening social inequalities. Lancet 1986;2:274-6.

5 Wilkinson RG. Class mortality differentials income, distribution and trend in poverty 1921-1981. Fournal of Social Policy 1989;18:307-35.

6 Independent inquiry into inequalities in health. Report. London: Stationery Office, 1998.

7 Illsley R, Baker D. Contextual variations in the meaning of health inequality. Soc Sci Med 1991;32:359-5.

8 Garcia Benavides F, Segura Benedicto A, Godoy Laserna C. Garcia Benavides F, Segura Benedicto A, Godoy Laserna C.
Estadísticas de mortalidad en España. Pequeños probleEstadisticas de mortalidad en Espana. Pequenos proble-
mas, grandes perspectivas. (Mortality Statistics in Spain. mas, grandes perspectivas.(Mortality Statistics in Spain.
Small problems and big perspectives) In: Alvarez-Dardet C, Porta Serra M, eds. Revisiones en Salud Pública C, Porta Serra

9 Navarro V, Benach J. Informe de la comisión cientifica de estudios de las desigualdades sociales en salud en España (Social inequalities in Spain). Rev Esp Salud Pública 1996; 70:505-636.

10 Borrell C, Plasencia A, Pasarini I, et al. Widening social inequalities in mortality: the case of Barcelona, a southern European city. $\mathcal{F}$ Epidemiol Community Health 1997;51:65967.

11 Regidor E, Gutierrez-Fisac JL, Rodriguez C. Increased socioeconomic differences in mortality in eight spanish provinces. Soc Sci Med 1995;41:801-7.

12 Blaxter M. Evidence of inequality in health from a national survey. Lancet 1987;ii:30-3.

13 Wannamethee G, Shaper AG. Self-assesment of health status and mortality in middle-aged British men. Int $\mathcal{F}$ EpiStatus and mortality in
demiol 1991;20:239-45.

14 Stronks K, Gunning-Shepers LJ. Should equity in health be target number 1? Eur F Public Health 1993;3:104-11.

15 World Health Organisation. Targets for health for all. Copenhagen: World Health Organisation, 1985

16 Mheen $\mathrm{H}$ van de, Sijmen AR, Mackenbach JP. Socioeconomic inequalities in perinatal and infant mortality from 1854 to 1990 in Amsterdam, The Netherlands. Eur F Public Health 1996;6:166-74.

17 Diderichsen F. Health and social Inequalities in Sweden. Soc Sci Med 1990;31:359-67.

18 Marmot MG, Davey Smith G, Stansfeld S, et al. Health inequalities among British civil servants: the Whitehall II study. Lancet 1991;337:1387-93.

19 Lahelma E, Karisto A. Morbidity and social structure. Recent trends in Finland. Eur F Public Health 1993;3:119Recent

20 Whitehead M. The health divide. London: Penguin, 1988.

21 Kunst AE, Mackenbach JP. Measuring socioeconomic inequalities in health. Copenhagen: World Health Organisation, ties in 1994.

22 Borrell C. Evolució de les desigualtats socials en salut a la ciutat de Barcelona 1983-1992, (Trends in social inequalities in health in Barcelona 1983-1992.) [MD thesis.] Barcelona: Universidad Autónoma de Barcelona, 1995

23 Lahelma E, Rahkonen O, Huuhka M. Changes in the social patterning of health? The case of Finland 1986-1994. Soc Sci Med 1997;44:789-99.

24 Ipiña A. Cuenta de la educación de 1993. Gran Canarias: Congreso Nacional de Economía e Instituto Canario de Administración pública, 1995.

25 Instituto Vasco de Estadistica. Información estadistica por temas. (http:www.eustat.es).
26 Stronks $\mathrm{K}$, Mheen $\mathrm{H}$ van de, Bos J van den, et al . Smaller rocioeconomic inequalities in health among women: the 27 Arber S. Class, paid employment and family roles: making sense of structural disadvantage, gender and health status. Soc Sci Med 1991;313:425-36.

28 Shchoenborn CA, Marano M. Current estimates from the National Health Interview Survey. Washington: Vital and Health Statistics, Series 10: no 166, 1987.

29 Armstrong BK, White E, Saracci R. Principles of exposure measurement in epidemiology. Oxford: Oxford University Press 1994:298-304.

30 Cavelaars AEJM, Kunst AE, Geurts JJM, et al. Differences in self-reported morbidity by educational level: A comparison of 11 Western European countries. F Epidemiol Community Health 1998;52:219-27.

31 Mackenbach JP. Socioeconomic health differences in the Netherlands: a review of recent empirical findings. Soc Sci Med 1992;34:213-26.

32 Kunst AE, Geurts JM, van der Berg J. International variation in socioeconomic inequalities in self reported health. F Epidemiol Community Health 1995;49:117-23.

33 Lahelma E, Arber S. Health inequalities among men and women in contrasting welfare states. Britain and three Nordic countries compared. Eur F Public Health 1994;4:21326

34 Aiach P, Curtis S. Social inequalities in self-reported morbidity: interpretation and comparison of data from Britain and France. Soc Sci Med 1990;31:267-74.

35 Lahelma E, Manderbacka K, Rahkonen O, et al. Comparisons of inequalities in health: evidence from national surveys in Finland, Norway and Sweden. Soc Sci Med 1994;38:517-24.

36 Arber S, Lahelma E. Inequalities in womens's and men's illhealth Britain and Finland compared. Soc Sci Med 1993:37:1055-68.

37 Mackenbach J, Kunst AE, Cavelaars AEJM, et al. Socioeconomic inequalities in morbidity and mortality in Western Europe. Lancet 1997;349:1655-9.

38 Gutierrez-Fisac JL, Regidor E, Rodriguez C. Trends in obesity differences by educational level in Spain. F Clin Epidemiol 1996;49:351-4.

39 Lundberg O. Causal explanation for class inequality in health-an empirical analysis. Soc Sci Med 1991;32:385-93.

40 Wilkinson RG. Unhealthy societies. The affliction of inequality. London: Routledge, 1996.

41 Instituto Nacional de Estadística. Desigualdad y pobreza en España. Estudio basado en las Encuestas de Presupuestos Familiares de 1973-74, 1980-81 y 1990-91. (Inequality and poverty in Spain. An study based on Family Budgets Surveys) Madrid: INE, 1991

42 Bartley M. Unemployment and ill health: understanding the relationship. I Epidemiol Community Health. 1994;48:333-7.

43 Anitua C, Aizpuru F. Encuesta de Vasca de Salud 1992. Resultados y Metodología. (Basque Health Survey 1992.

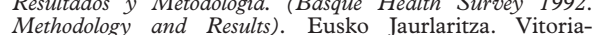
Gethodology and Results). Eusko Jaurlaritza.

44 Blank N, Diderichsen F. The prediction of different experiences of longterm illness: a longitudinal approach in Sweden. F Epidemiol Community Health. 1996;50:156-61.

45 Arber S. Integrating nonemployment into research on health inequalities. Int f Health Serv 1996;26:445-81.

46 Schrijvers CTM, Mheen $\mathrm{H}$ van de, Stronks K, et al. Socioeconomic inequalities in health in the working population: the contribution of working conditions. Int $\mathcal{F}$ Epidemiol 1998;27:1011-18.

47 Ayala L, Ruiz-Huerta J, Martinez R. El mercado de trabajo y la distribución de la renta en España en los años noventa (Labour market and income distribution in Spain in the nineties). Ekonomiaz 1998:40:104-33.

48 Wilkinson RG. Health inequalities: relative or absolute material standards. BMF 1997; 314:591-5.

49 Ferrie JE, Shipley MJ, Marmot MG, et al. Health effects of anticipation of job change and non-employment: longitudinal data from the Whitehall study. BMF 1995;311:1264-9. 